\title{
Pemodelan Pengaturan Kecepatan Motor Induksi dengan Pulse Widht Modulation dengan Matlab
}

\author{
Zainal Abidin *) \\ ${ }^{*}$ Dosen Fakultas Teknik Universitas Islam Lamongan \\ Program Studi Teknik Elektro \\ Email: zainalabidin@unisla.ac.id
}

\begin{abstract}
ABSTRAK
Kajian tentang metode dan pemodelan alternatif pengaturan kecepatan motor dengan metode pengaturan tegangan yang saat ini digunakan yakni metode Volt/Hertz konstan dengan Pulse With Modulation (PWM) dengan beberapa keuntungan dan kerugian dan menunjukkan keuntungan dan kerugian yang mungkin untuk mencapai metode baru dibandingkan dengan model yang dipakai saat ini.
\end{abstract}

Karakteristik penggunaan PWM tersebut dapat dipelajari bersama dengan penggunaan pemodelan Matlab/ Simulink.

\section{Kata kunci : pengaturan kecepatan, PWM, Volt/Hertz,}

\section{PENDAHULUAN}

Metode pengaturan kecepatan motor induksi saat ini dibatasi maksimal 4 Ampere saat diinjeksikan ke motor karena panas yang berlebihan pada sisi kontrol. Saat ini ada upaya untuk meningkatkan arus maksimum yang diizinkan pada unit kontrol hingga 16 A sehingga dimungkinkan penggunaan motor induksi dapat digunakan untuk keperluan yang lebih besar, misalkan pompa dan beberapa motor dengan daya besar. Sangat penting juga meminimalkan kerugian daya mesin yang dibutuhkan saat melayani beban.

Analisis pasar menunjukkan bahwa sebagian besar dari semua aplikasi motor industri menggunakan motor AC induksi. Alasan untuk hal ini mencakup ketahanan yang tinggi, kehandalan, harga rendah dan efisiensi yang tinggi, $\eta>90 \%$ lebih disukai untuk mengurangi biaya operasi dan memaksimalkan keuntungan jangka panjang bagi pengguna. Namun, penggunaan motor induksi juga memiliki kelemahan, terutama dalam pengendalian yang sulit, karena model matematika yang kompleks, perilaku non linier selama efek saturasi dan osilasi parameter listrik yang tergantung pada pengaruh fisik suhu.

\section{Metode Teknik Pengaturan pada Motor Induksi}

Pengaturan kecepatan motor induksi dapat dilakukan dengan beberapa metode diantaranya : Pengaturan tegangan, pengaturan frekuensi, pengaturan vektor, merubah jumlah kutub, resistansi rotor, doubly fed motor dan rangkaian Metode Kramer .

\section{Model Dinamis Motor Induksi}

Dalam kerangka acuan stasioner ( $\alpha \beta$-koordinat), model dinamis motor induksi 3-fase dapat digambarkan sebagai berikut :,

$$
\frac{d}{d t}\left[\begin{array}{l}
i_{s} \\
\phi_{r}
\end{array}\right]=\left[\begin{array}{ll}
a_{11} & a_{12}-j \rho \omega_{r} \\
a_{21} & a_{22}+j \omega_{r}
\end{array}\right]\left[\begin{array}{c}
i_{s} \\
\phi_{r}
\end{array}\right]+\left[\begin{array}{c}
b_{s} \\
0
\end{array}\right] v_{s}
$$

di mana:

$$
\begin{array}{ll}
a_{11}=-\left(\frac{R_{s}}{\sigma L_{s}}-\frac{1-\sigma}{\sigma \tau_{r}}\right) & a_{12}=\frac{L_{m}}{\sigma L_{s} L_{r} \tau_{r}} \\
a_{21}=\frac{L_{m}}{\tau_{r}} & a_{22}=-\frac{1}{\tau_{r}} \\
b_{s}=\frac{1}{\sigma L_{s}} &
\end{array}
$$

$R_{s}, R_{r}$ : resistansi stator dan rotor per phase

$L_{s}, L_{r} \quad$ : induktansi stator dan rotor per phase

$L_{m} \quad$ : induksi magnet /fase

$\omega_{r} \quad$ : sudut kecepatan motor

$\tau_{r} \quad:$ waktu konstan rotor $\left(=L_{r} / R_{r}\right)$

$\rho \quad: L_{m} / \sigma L_{s} L_{r}$

$\sigma \quad:$ kebocoran konstan $\left(=1-L_{m}{ }^{2} / L_{s} L_{r}\right)$

variabel input dan statis motor sebagai berikut:
Arus stator
$: i_{s}=i_{s \alpha}+j i_{s \beta}$
Tegangan stator $: v_{s}=v_{s \alpha}+j v_{s \beta}$
Flux rotor $\quad: \Phi_{r}=\Phi_{r \alpha}+j \Phi_{r \beta}$ 
Rangkaian Ekivalen Motor Induksi

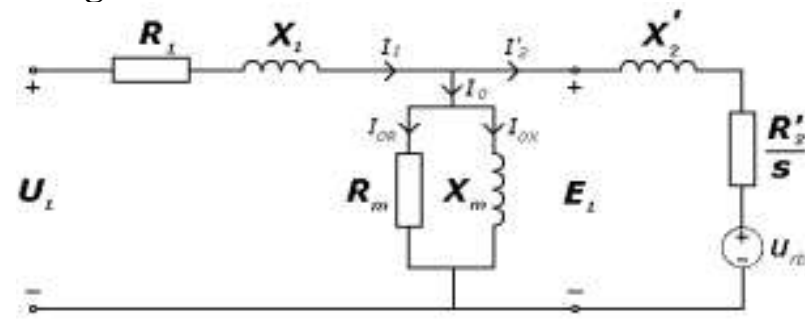

Gambar 1. Rangkaian Ekivalen Motor Induksi

Dimana :

$U_{1} \quad=$ Tegangan terminal stator

$E_{1} \quad=$ emf stator yang dibangkitkan

$R_{l} \quad=$ resistansi stator

$X_{I} \quad=$ reaktansi stator

$R_{m} \quad \quad=$ rugi inti besi

$X_{m} \quad=$ reaktansi pemagnetan

$R_{2}^{\prime} \quad=$ resistansi rotor $\mathrm{dg}$ referensi rotor

$X_{2}^{\prime}=$ reaktansi arus bocor rotor dengan referensi stator

$u_{r b} \quad=$ e.m.f pada rotor

$I_{0} \quad=$ Arus magnetisasi $I_{O X}$ and rugi inti $I_{O R}$ current components

$I_{1} \quad=$ Arus stator

$I_{2}^{\prime}=$ arus rotor $\mathrm{dg}$ referensi stator

Beberapa karakteristik penting pada kondisi tunak motor induksi polyphase termasuk variasi arus, kecepatan dan rugi-rugi seperti perubahan beban dan torsi, dan saat torsi maksimum starting. Perhitungan karakteristik didapat dari rangkaian ekivalen. Seluruh perhitungan dapat dibuat dengan basis per fase dengan asumsi mesin beroperasi seimbang. Jumlah total diperoleh dari faktor pengali yang tepat.

Rangkaian ekivalen seperti gambar 1 biasanya digunakan untuk analisis. Kerugian inti, yang sebagian besar terjadi pada stator, rugi gesek, rugi celah udara adalah kerugian yang dihitung dalam perhitungan efisiensi motor. Diagram aliran daya untuk motor induksi dapat dilihat pada gambar 2 berikut :

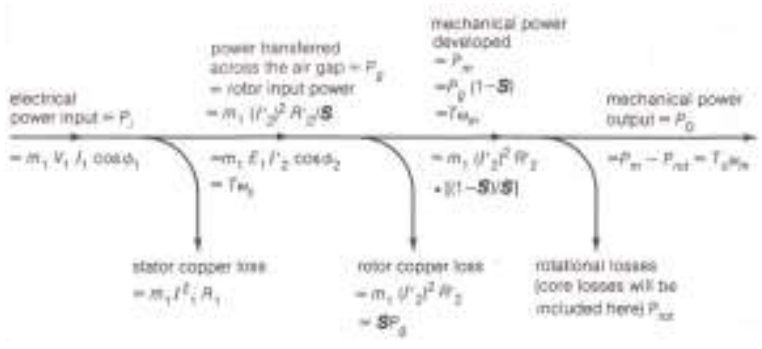

Gambar 2. Aliran daya motor induksi
Pada gambar 2 di atas, $m_{1}$ adalah jumlah fase stator, $\Phi 1$ adalah sudut faktor daya antara U1 dan I1, $\Phi 2$ adalah sudut faktor daya antara E1 dan 'I2, $\mathrm{T}$ adalah torsi elektromagnetik internal yang dikembangkan, $\omega$ s adalah kecepatan sudut dalam radian sinkron mekanik per detik, dan $\omega_{\mathrm{m}}$ adalah kecepatan rotor aktual mekanik yang diberikan oleh $\omega$ s $(1-S)$.

Total daya $\mathrm{Pg}$ (watt) ditransfer melintas celah udara dari stator daya total dalam watt ditransfer melintasi celah udara dari stator adalah berbeda antara $P i$ input daya listrik dan rugi tembaga stator. Pg adalah total daya input rotor yang disipasi $R_{2}{ }^{\prime} / \mathrm{S}$ pada tiap fase.

$$
P_{g}=m_{1}\left(I_{2}^{\prime}\right)^{2} \frac{R_{2}^{\prime}}{S}=T \omega_{s}
$$

Dimana $\mathrm{T}$ adalah torsi elektromagnetik internal yang ditimbulkan oleh motor, dan $\omega$ s adalah kecepatan sinkron dalam radian/dtk. Dengan mengurangkan rugi tembaga total rotor, dengan $m_{1}\left(I_{2}^{\prime}\right)^{2} R_{2}{ }^{\prime}=S P_{g}$, Dari persamaan 2.2 untuk $\mathrm{P}_{\mathrm{g}}$, kita mendapatkan daya mekanik :

$P_{m}=P_{g}(1-S)=T \omega_{m}=m_{1}\left(I_{2}^{\prime}\right)^{2} R_{2}^{\prime} \frac{(1-S)}{S}$

Pada kondisi ini daya banyak diserap oleh resistansi $R_{2}^{\prime}(1-S) / S$, yang terhubung dengan beban . Dari persamaan 2.3, kita melihat bahwa slip (1-s) diubah menjadi daya mekanik dan slip S didisipasi sebagai rugi tembaga pada rotor. Dari sini kita menyimpulkan bahwa operasi motor induksi dengan nilai slip tinggi menjadi tidak efisien..

Total rugi putaran termasuk rugi inti dikurangkan dari $\mathrm{P}_{\mathrm{m}}$ untuk mendapatkan daya output $\mathrm{P}_{\mathrm{o}}$ yang terjadi pada poros mekanis :

$$
P_{o}=P_{m}-P_{r o t}=T_{o} \omega_{m}
$$

Efisiensi daya motor induksi diperoleh dengan perbandingan daya output dan daya input :

$$
\eta=\frac{P_{o}}{P_{i}}
$$




\section{Model Dinamik Motor Induksi}

Dalam rangkaian stator, resitansi $R_{s}$ kumparan stator bernilai sama pada ketiga fasenya. Dari hukum induksi, berikut bahwa bagian dari tegangan stator yang tidak dihamburkan dalam tahanan stator akan membentuk fluks pada belitan stator. Oleh karena itu, dengan vs sebagai vektor ruang tegangan stator, hubungan berlaku:

$$
\nu_{s}^{s}-\boldsymbol{R}_{s} \boldsymbol{i}_{s}-\frac{d \boldsymbol{\psi}^{s}}{d t}=0 \ldots \ldots \ldots \ldots \ldots
$$

where $i_{s}^{s}$ and $\psi_{s}^{s}$ are the space vectors for stator current and stator flux linkage respectively. The rotor circuit, with winding resistance $R_{r}$, can be treated in a similar way. Suppose that the rotor is observed from a coordinate system (rotor coordinates) which rotates with the same speed as the rotor $\omega_{r}$. Let us denote rotor coordinates with superscript " $r$ ". As the coordinate system is rotor-fixed, there will be no induced voltage due to the rotation, so the same relation as for the stator must hold, but with "s $\rightarrow r$ ":

di mana $i_{\mathrm{s}}{ }^{\mathrm{s}}$ dan $\psi_{\mathrm{s}}{ }^{\mathrm{s}}$ adalah vektor ruang masingmasing untuk arus stator dan hubungan fluks stator. Sirkuit rotor, dengan resistansi belitan Rr, dapat diperlakukan dengan cara yang serupa. Misalkan rotor diamati dari sistem koordinat (koordinat rotor) yang berputar dengan kecepatan yang sama dengan rotor $\omega r$. Koordinat rotor ditunjukkan dengan superscript " $r$ ". Karena sistem koordinat adalah rotor-fix, tidak akan ada tegangan yang disebabkan oleh rotasi, sehingga hubungan yang sama seperti untuk stator harus dipertahankan, dengan hubungan "s $\rightarrow \mathrm{r}$ ":

$$
v_{r}^{r}-R_{r} i_{s}^{s}-\frac{d \psi_{r}^{r}}{d t}=0
$$

Dimana $v_{r}^{r}, i_{r}^{r}$ dan $\psi_{r}^{r}$ adalah tegangan rotor, arus dan vektor ruang flux secara berurutan. Namun, ketika kumparan rotor dihubung singkat, $v_{r}{ }^{r}=0$. Maka, transformasi $i_{r}^{r}$ dan $\psi_{r}^{r}$ berada pada koordinat stasioner. Transformasi $\alpha \beta$ menggunakan posisi rotor $\theta_{r}=\int \omega_{r} d t$ :

$$
i_{r}^{s}=e^{j \theta_{r}} i_{r}^{r}, \quad \psi_{r}^{s}=e^{j \theta_{r}} \psi_{r}^{r} \ldots \ldots \ldots \ldots
$$

Persamaan (7) ditransformasikan menjadi :
$0-\boldsymbol{R}_{r} e^{-j} \theta_{r} \ddot{i}_{r}^{s}-\frac{d\left(e^{-j} \theta_{r} \psi_{r}^{s}\right)}{d t}=0 \Rightarrow$
$-\boldsymbol{R}_{r} e^{-j \theta_{r}} i_{r}^{s}-\left(-j \omega_{r} e^{-j} \theta_{r} \psi_{r}^{s} \frac{d\left(e^{-j} \theta_{r} \psi_{r}^{s}\right)}{d t}\right)=0 \Rightarrow$

$j \omega_{r} \psi_{r}^{s}-R_{r} i_{r}^{s}-\frac{d \psi_{r}^{s}}{d t}=0$

Motor induksi is digambarkan dengan persamaan

$$
\begin{aligned}
& \frac{d \psi_{s}^{s}}{d t}=v_{s}^{s}-R_{s} i_{s}^{s} \quad \text { (stator) } \\
& \frac{d \psi_{r}^{s}}{d t}=j \omega_{r} \psi_{r}^{s}-R_{r} i_{r}^{s} \quad \text { (rotor) } \\
& \ldots \text { (10) }
\end{aligned}
$$

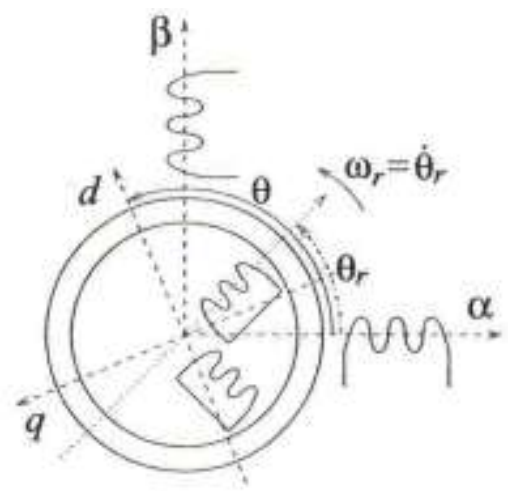

\section{Gambar 3. Mesin Induksi}

Saat kumparan rotor direferensikan pada stator, kumparan rotor digambarkan dengan kumparan dengan arah $\alpha$ dan $\beta$, (gambar 3). Dengan menganggap kondisi magnet linier, fluks celah udara $\psi_{\alpha}^{s}$ dapat ditentukan sebagai :

$$
\psi_{\alpha}^{s}=L_{m} i_{m}^{s}, \quad i_{m}^{s}=i_{s}^{s}+i_{r}^{s}
$$

Dimana $L_{m}$ adalah induktansi bersama antara stator dan rotor, magnetizing inductance, dan $i_{m}{ }^{s}$, adalah arus magnet. Fluks stator adalah jumlah dari fluks celah udara dan fluks bocor stator, yang kemudian dalam kondisi linier magnetik secara proporsional hanya arus stator. Hal tersebut sama untuk gulungan rotor 


$$
\begin{aligned}
& \psi_{s}^{s}=L_{m} i_{m}^{s}+L_{s i} i_{s}^{s} \\
& \psi_{r}^{s}=L_{m} i_{m}^{s}+L_{r} i_{r}^{s}
\end{aligned}
$$

Dimana $L_{s l}$ dan $L_{r l}$ adalah induktansi bocor stator dan rotor. Induktansi bocor sekitar $10 \%$ dari $L_{m}$ atau kurang. Bisa juga dengan $L_{s}=L_{m}+L_{s l}$ dan $L_{r}=L_{m}+L_{r t}$ sebagai induktansi diri dari stator dan rotor. Hubungan ini dapat digambarkan sebagai :

$$
\begin{aligned}
& \psi_{s}^{s}=L_{s} i_{s}^{s}+L_{m} i_{r}^{s} \\
& \psi_{r}^{s}=L_{m} i_{s}^{s}+L_{r} i_{r}^{s}
\end{aligned}
$$

Dengan menggabungkan persamaan 12) dan 10, dengan menganggap induktansi konstan, maka :

$$
\begin{aligned}
& v_{s}^{s}-R_{s} i_{s}^{s}-L_{s l} \frac{d i_{s}^{s}}{d t}-L_{m} \frac{d i_{m}^{s}}{d t}=0 \\
& j \omega_{r} \psi_{r}^{s}-R_{r} i_{r}^{s}-L_{r l} \frac{d \boldsymbol{i}_{r}^{s}}{d t}-L_{m} \frac{d \boldsymbol{i}_{m}^{s}}{d t}=0
\end{aligned}
$$

Persamaan tersebut menggambakan rangkaian persamaan dinamik yang digambarkan pada gambar 4. Karena ada tiga induktansi yang terhubung " $T$ ", maka rangkaian ini disebut " $T$ equivalent circuit ".

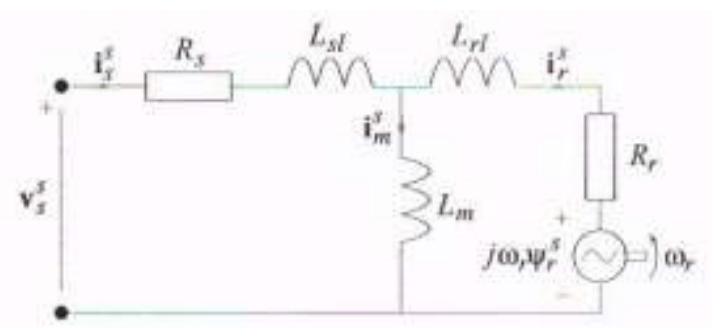

\section{Gambar 4 . Rangkaian T Dinamik untuk motor induksi}

\section{Pemodelan Simulink}

Dalam simulasi kita buat konverter AC/ AC yang terhubung ke jaringan DC dengan Matlab/ Simulink (gambar 6) dengan sebuah penyearah diode dan inverter PWM 3 fase yang mengatur frekuensi dan tegangan output dengan penyearah dioda dan inverter PWM 3 fase yang mengendalikan frekuensi dan besarnya output tegangan. Model mesin induksi didasarkan pada persamaan dari model mesin induksi dinamis. Untuk generasi pulsa PWM teknik yang ditunjukkan pada (gambar 5) digunakan membandingkan tegangan kontrol sinusoidal (pada frekuensi output yang diinginkan dan sebanding dengan besarnya tegangan output) dengan bentuk gelombang segitiga pada frekuensi switching yang dipilih.

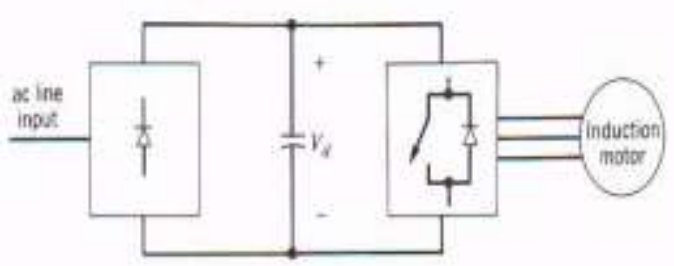

\section{Gambar 5. Konverter PWM 3-phase PWM dengan DC-Link}

Pada tegangan output inverter PWM, harmonik berada pada frekuensi tinggi, riak pada arus motor biasanya kecil karena reaktansi kebocoran tinggi pada frekuensi ini. Karena harmonik tegangan frekuensi tinggi ini dapat memiliki amplitudo setinggi atau bahkan lebih tinggi dibandingkan dengan komponen frekuensifundamental, maka kerugian zat besi (arus eddy dan histeresis pada stator dan besi rotor) mendominasi. Faktanya, total kerugian akibat harmonisa bahkan mungkin lebih tinggi dengan inverter PWM dibandingkan dengan inverter gelombang persegi. Perbandingan ini tentu saja akan tergantung pada kelas desain motor, sifat material magnetik, dan frekuensi switching. Karena kerugian harmonik tambahan ini, umumnya direkomendasikan motor standar berkisar 5-10\%.

Dalam drive PWM, torsi berdenyut yang dikembangkan kecil dalam amplitudo dan berada pada frekuensi tinggi (dibandingkan dengan yang mendasar). Oleh karena itu, seperti yang ditunjukkan dalam persamaan (10), mereka menghasilkan sedikit denyut kecepatan karena inersia motor.

Amplitudokecepa $\tan =k \frac{\text { amplitudo torsi }}{\text { frekuensi } \times \text { inertia }}$

Berikut ini tabel perbandingan pengaturan frekuensi pada kendali motor induksi : 
Tabel 2. Perbandingan Pengaturan Frekuensi

\begin{tabular}{|l|c|c|c|}
\hline \multicolumn{1}{|c|}{$\begin{array}{c}\text { Parame } \\
\text { ter }\end{array}$} & PWM & $\begin{array}{c}\text { Gelombang } \\
\text { Persegi }\end{array}$ & CSI \\
\hline $\begin{array}{l}\text { Input power } \\
\text { factor }\end{array}$ & + & - & -- \\
\hline $\begin{array}{l}\text { Torque } \\
\text { pulsation }\end{array}$ & ++ & - & - \\
\hline $\begin{array}{l}\text { Multi motor } \\
\text { capability }\end{array}$ & + & + & - \\
\hline Regeneration & - & - & ++ \\
\hline $\begin{array}{l}\text { Short-circuit } \\
\text { protection }\end{array}$ & - & - & ++ \\
\hline $\begin{array}{l}\text { Open-circuit } \\
\text { protection }\end{array}$ & + & + & - \\
\hline $\begin{array}{l}\text { Ability to } \\
\text { handle } \\
\text { undersized } \\
\text { motor }\end{array}$ & + & + & - \\
\hline $\begin{array}{l}\text { Ability to } \\
\text { handle } \\
\text { oversized } \\
\text { motor }\end{array}$ & - & - & - \\
\hline $\begin{array}{l}\text { Efficiency at } \\
\text { low speeds }\end{array}$ & - & + & + \\
\hline $\begin{array}{l}\text { Size and } \\
\text { weight }\end{array}$ & + & + & -- \\
\hline $\begin{array}{l}\text { Ride-trough } \\
\text { capability }\end{array}$ & + & - & - \\
\hline
\end{tabular}

Gambar 6 menunjukkan model simulink untuk kendali motor induksi :

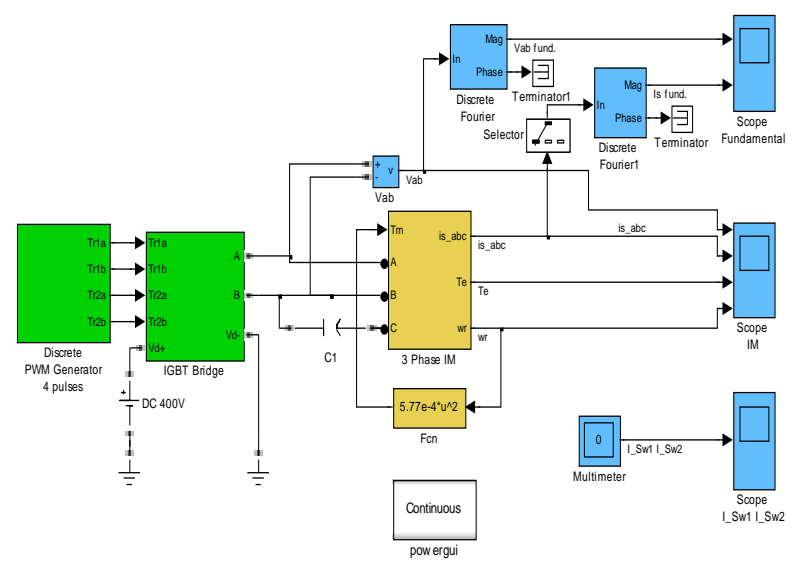

Gambar 6. Model simulink Motor Induksi

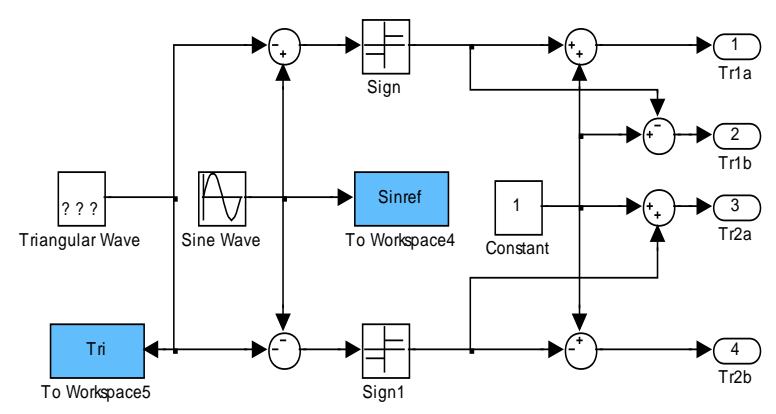

Gambar 7. Model diskrit pembangkit PWM 4 pulsa

\section{HASIL DAN PEMBAHASAN}

Dari hasil running program Matlab / Simulink didapatkan hasil sebagai berikut :

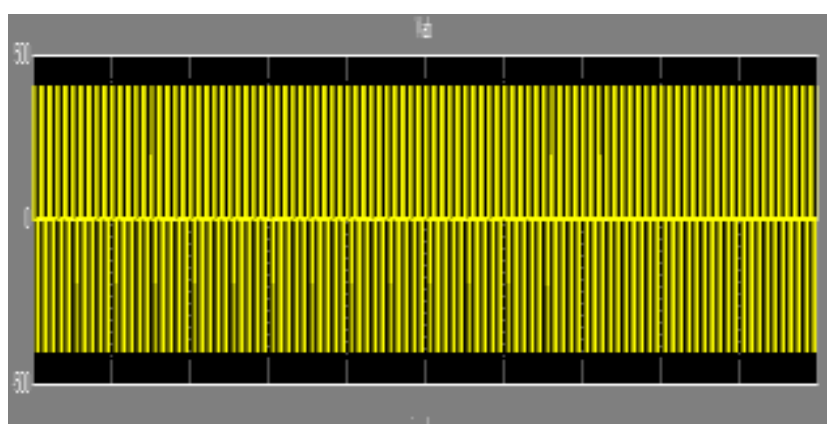

Gambar 7. Profil output tegangan (V)

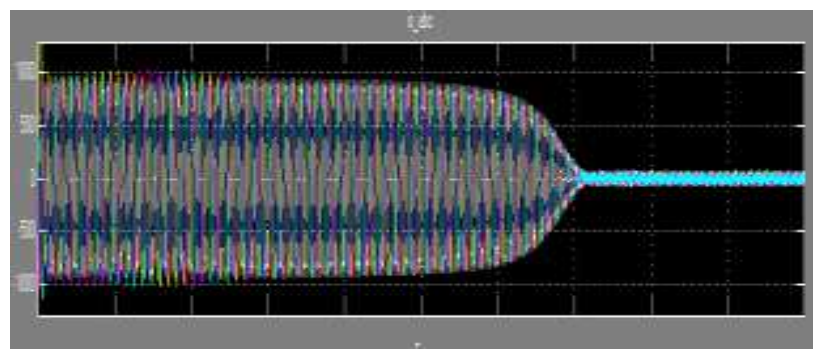

Gambar 8. Profil Arus output Kendali Motor Induksi

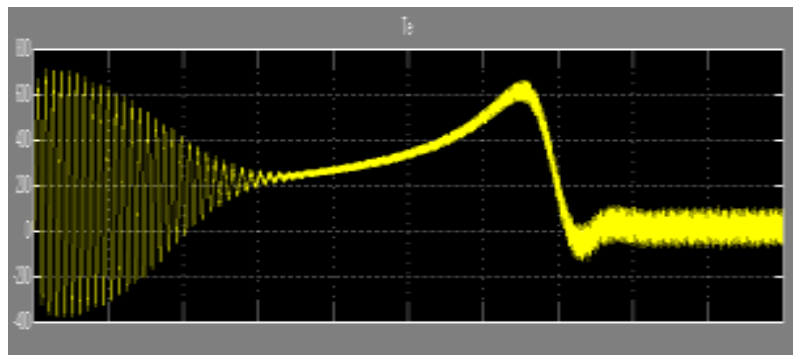

Gambar 9. Torsi Output Kinerja Motor Induksi

\section{Analisis}

Model PWM tegangan-frekuensi (V / f) dapat digunakan efektif dalam pengaturan kecepatan motor induks. Dapat meningkatkan arus yang 
dipasok ke mesin induksi hingga 16 ampere dimungkinkan tanpa mengganggu pengaturan kecepatan, dan dapat mengurangi panas di dalam rangka mesin. Keluaran 3 fase memberikan umpan yang lebih baik ke mesin induksi tanpa komponen tambahan yang diperlukan pada motor dan juga menghasilkan torsi awal yang lebih tinggi dan amplitudo denyut kecepatan yang berkurang.

\section{PENUTUP}

\section{Simpulan}

Model pengaturan kecepatan dengan proporsional V/F memungkinkan terjadi pencapaian peningkatan arus yang dipasok ke motor induksi sesuai standar tanpa ada penumpukan panas yang berlebihan. Output tegangan 3 fase dari inverter PWM akan mengurangi denyut kecepatan dan menghasilkan torsi awal yang lebih tinggi sehingga memungkinan mengurangi kapasitas daya motor. Untuk memperbaiki model pengaturan motor induksi diperlukan solusi yang menyediakan algoritma kecepatan tinggi, resolusi tinggi, dan lebih sedikit sensor untuk mengurangi biaya sistem. Peningkatan dapat dengan mudah dilakukan dalam perangkat lunak dan jumlah bagian juga berkurang karena sistem digital dapat menangani beberapa fungsi pada chip mikrokontroller.

\section{PUSTAKA}

[1] Sadarangani, C., "Electrical Machines", Royal Institute of Technology, Stoc kholm, Sweden, (2000)

[2] Mohan N, Undeland, T. M. and Robbins, W. P., "Power Electronics", John Wiley \& Sons Inc., USA, (2003)

[3] Harnefors, L., "Control of Power Electronic Converters and Variable-Speed Drives", Mälardalen University, Västerås, Sweden, (1999)

[4] Slemon, G. R, "Electric Machines and Drives",Addison-Wesley Publishing Company, USA, (1992)

[5] Sarma, M. S, "Electrical Machines, SteadyState Theory and Dynamic Performance", West Publishing Company, USA, (1994)

[6] El-Hawary, M. E, "Principled of Electric Machines with Power Electronic App.", John Wiley \& Sons Inc, USA, (2002) 
